\title{
A FURTHER STUDY OF FITNESS OF CHROMOSOMALLY POLYMORPHIC AND MONOMORPHIC POPULATIONS OF DROSOPHILA PSEUDOOBSCURA *
}

\author{
THEODOSIUS DOBZHANSKY and OLGA PAVLOVSKY \\ Department of Zoology, Columbia University, New York
}

\section{INTRODUCTION}

Received I4.ii.6I

THE present report is a sequel to that of Beardmore, Dobzhansky and Pavlovsky (1960), who made an exploratory study of the fitness of chromosomally polymorphic and monomorphic experimental populations of Drosophila pseudoobscura. The populations of this previous study were kept for about 3 years in wood-and-glass cages, each with I 5 cups containing Drosophila culture medium. A cup of fresh medium was introduced, and one with used-up medium removed, on alternate days. The populations each contained some 1000-4000 adult flies, and at least ten times as many eggs and larvæ. The polymorphic populations had flies with $\mathrm{AR}$ and with $\mathrm{CH}$ gene arrangements in their third chromosomes; the homokaryotypes $\mathrm{AR} / \mathrm{AR}$ and $\mathrm{CH} / \mathrm{CH}$, and the heterokaryotype $\mathrm{AR} / \mathrm{CH}$, were represented with frequencies approaching those demanded by the Hardy-Weinberg rule. The monomorphic populations had only $\mathrm{AR}$, or only $\mathrm{CH}$, chromosomes. The study has shown that the polymorphic populations produced more flies per cup of culture medium than did the monomorphic ones. Individual flies in the polymorphic populations were neither consistently larger nor heavier than in the monomorphic ones; however, since the former produced more flies, they produced also a greater fly biomass. Furthermore, the variances of the numbers of the flies produced per cup, and the variances of individual weights and of sizes were lower in the polymorphic than in the monomorphic populations. The conclusion seems warranted that, under the conditions of the experiments, the polymorphic populations exploit more efficiently the resources of their environment than do the monomorphic populations.

The environment offered to Drosophila in the experimental population cages is a highly competitive one. The food given is sufficient to sustain the development to the adult stage of fewer than Io per cent, though probably of more than I per cent, of the eggs deposited. However, the adult flies probably do not starve; a part of the surface of the yeasted food medium is almost always free of feeding or ovipositing flies. In the experiments to be described below the situation is different. In these experiments we have used a variant

* The work under Contract No. AT-(30-1)-I I5I, U.S. Atomic Energy Commission. 
of the technique first proposed by Buzzati-Traverso (1955), and developed by Carson (1958) and his collaborators. Here the adult flies are crowded in a space so confined that they interfere with each other, probably largely mechanically. After an initial spurt of oviposition, the number of the eggs deposited in the populations drops, and many eggs are probably trampled by the adults and do not hatch. The result is that the population sizes become limited, chiefly owing to the competition among the adults rather than among the larvæ. We hope to show that under these conditions the polymorphic populations are superior in fitness to the monomorphic ones.

\section{EXPERIMENTAL PROCEDURE}

The material for the present experiment was derived from the same experimental populations which were utilised by Beardmore, Dobzhansky and Pavlovsky (1960). In December of $195^{8}$ and in January of 1959, fifty pairs of adult flies were taken from each of the populations Nos. I73 and I8I (polymorphic), I75 and I80 (monomorphic for AR), and 177 and 182 (monomorphic for $\mathrm{GH}$ ). Each group of fifty "founders" were placed in culture bottles with fresh food. Twice a week (on Mondays and Thursdays, or on Tuesdays and Fridays), the adult flies were transferred, without etherisation, to fresh culture bottles. The eggs which they deposited were allowed to develop and to yield adults. When the hatching of the progeny began, the bottles were emptied twice a week, the flies etherised, females and males separated, weighed and added to the adult population. Once a week, the adult population was etherised, females and males separated, counted, weighed and placed in a bottle with fresh food. The adult ovipositing flies were thus always in a single bottle with fresh food, while 7-8 bottles in each series contained eggs, larvæ, pupæ and newly hatched adults. All the bottles were kept in incubators at $25^{\circ} \mathrm{C}$. The weighings were made on a chemical balance, with a precision of o.I mg.

The number of flies in the experimental populations underwent characteristic changes, very much the same in all cases. The course of events in the populations Nos. 180,181 and 182 is represented graphically in fig. I. Being relatively uncrowded, the $5^{\circ}$ pairs of "founders" of each population oviposit freely. In about 4 weeks from the start, the numbers of the adult flies begin to grow rapidly, owing to the ecclosion of young flies. By the Ioth-I 2 th week the adult population increases to 1000 or more flies. This causes a fearful overcrowding. The 3-day intervals between the transfers of the flies to fresh cultures suffice to have the whole surface of the nutrient medium in the bottles covered by cadavers of the flies which have died during the interval. The numbers of progeny hatching from the bottles in which the parents were so overcrowded become small, apparently because relatively few eggs are laid, and many of them 


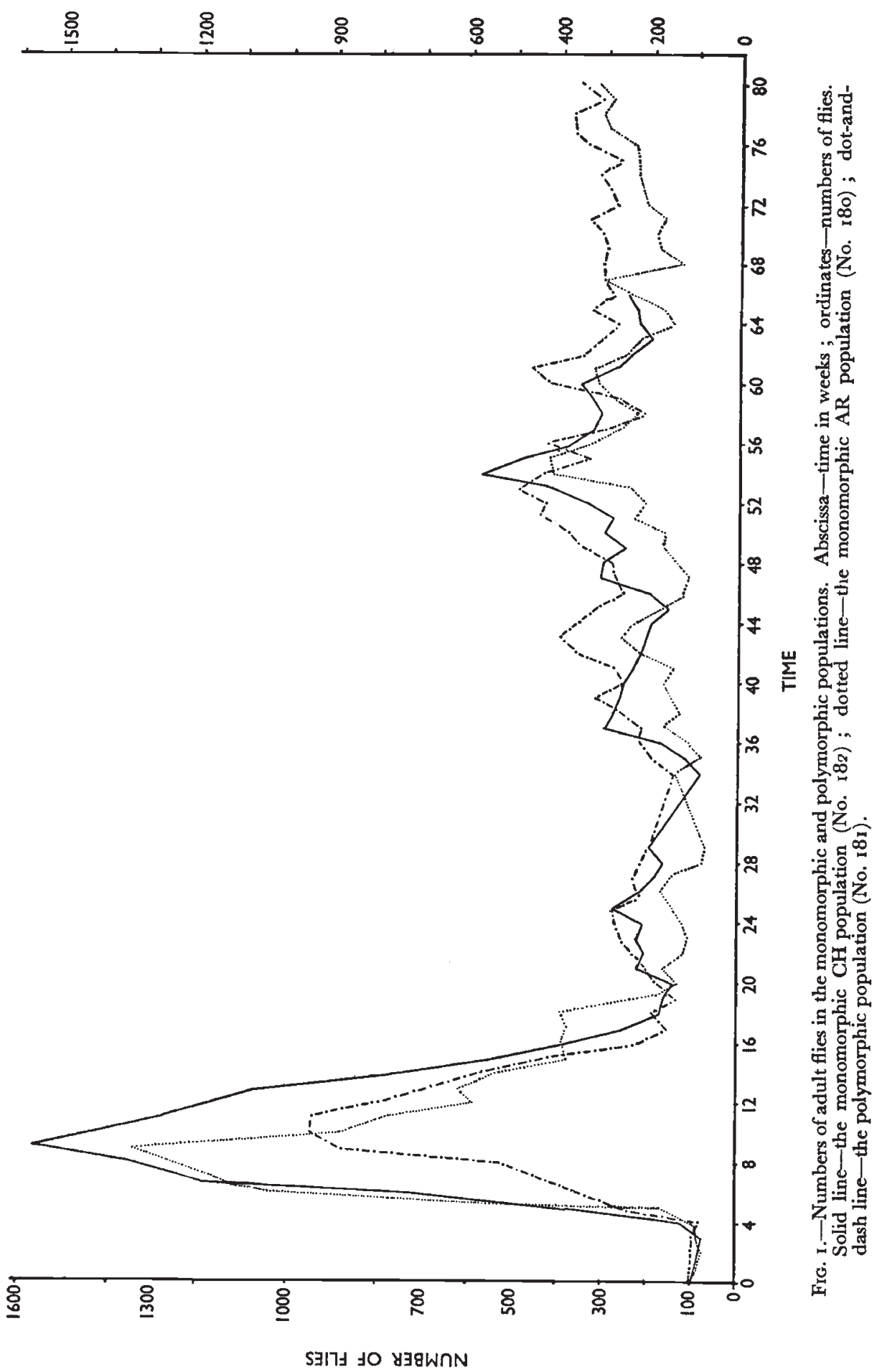


fail to develop. By about the $15^{\text {th- }} 18$ th week the adult population is reduced back to about roo-30o flies.

The diminished crowding of the adults permits more eggs to be laid and to develop. From then on, the populations undergo rather irregular oscillations, the character of which can be seen in fig. I more easily than it can be described in words. The experiments were continued for 70 to 85 weeks. Towards the middle of this period, a trend became apparent towards a gradual increase in the population size, as can be seen in fig. I. Whether this trend was due to a progressing genetic adaptation to the experimental conditions, or to the improving art of the experimenter is uncertain; the former is more likely to be the correct explanation than the latter.

Let us now ignore the first 18 weeks of the existence of the populations, during which the populations first "explode" and then "crash". From the 18th week on, the oscillations do not, at first sight, show a clear advantage of any one population (fig. I). A more careful inspection discloses, however, that the polymorphic population (No. 181) had often most flies, while the monomorphic AR population (No. 180) had normally fewest, the monomorphic CH (No. 182) being intermediate. This visual impression can be tested statistically.

Tables $\mathrm{I}$ and 2 show the means and their standard errors for the following parameters: the numbers of flies of either sex in the adult populations and their weights (as determined from the weekly counts and weighings); the numbers of flies of either sex hatched from the pupæ per half-week, and their weights; the tables also show the mean weights of a female and of a male fly in the populations; these means are obtained simply by division of the total weight by the number of individuals of a given sex. Because of the trend towards a gradual increase in the population sizes (see above), we have computed the means only for the populations which were studied strictly simultaneously. As shown in fig. I, population No. 182 had to be destroyed 14 weeks before Nos. 181 and 180 . Therefore the data shown in table 2 take into consideration only the time interval when all these populations were more than 18 weeks but less than 66 weeks old.

\section{THE FIRST EXPERIMENT}

The three populations, No. I73 (polymorphic), No. I75 (monomorphic AR), and No. 177 (monomorphic $\mathrm{CH}$ ) had similar histories while they lived in the population cages, and the bottle populations derived from them were studied simultaneously. Table I reports the sizes of the adult populations and the birth rates of the adults in these populations. The means are calculated for 48 weeks (18th-7oth; no counts were taken from the $25^{\text {th }}$ to the 29 th week).

The polymorphic population contained on the average more adult flies, both females and males, than the monomorphic CH population, and the latter more than the monomorphic AR population. However, 
while the differences between the polymorphic and the monomorphic $\mathrm{CH}$ are not statistically significant, those between the monomorphic $\mathrm{CH}$ and the monomorphic AR are statistically assured. The same sequence, polymorphic $>$ monomorphic $\mathrm{CH}>$ monomorphic $\mathrm{AR}$, is observed also for the total weights of the adult females and of males, the numbers of females and of males born (i.e. hatched from pupæ) per unit time, and the weights of females and males born per unit time (table I). The differences between the polymorphic and the

TABLE I

Number and weight (in mg.) of the fies in the populations. First experiment

\begin{tabular}{|c|c|c|c|c|}
\hline & & $\begin{array}{l}\text { Polymorphic } \\
\text { AR/CH(1 73) }\end{array}$ & $\begin{array}{c}\text { Monomorphic } \\
\text { AR (175) }\end{array}$ & $\begin{array}{l}\text { Monomorphic } \\
\mathrm{CH}(\mathrm{I} 77)\end{array}$ \\
\hline Total population & $\begin{array}{l}\text { q9 } \\
\text { d0 }\end{array}$ & $\begin{array}{l}217.5 \pm 7 \cdot 1 \\
139.9 \pm 6 \cdot 0\end{array}$ & $\begin{array}{l}\text { I } 55^{\circ} 4 \pm 4.3 \\
\text { I06.0 } \pm 4.4\end{array}$ & $\begin{array}{l}216 \cdot 8 \pm 5 \cdot 1 \\
132 \cdot 0 \pm 4 \cdot 3\end{array}$ \\
\hline Total weight & $\begin{array}{l}\text { 우우 } \\
\text { ơ }\end{array}$ & $\begin{array}{l}265 \cdot 2 \pm 9 \cdot 2 \\
124.3 \pm 6 \cdot 1\end{array}$ & $\begin{array}{r}\mathrm{I} 92 \cdot 9 \pm 5 \cdot \mathrm{I} \\
92 \cdot 3 \pm 3 \cdot 9\end{array}$ & $\begin{array}{l}247 \cdot 3 \pm 6 \cdot 1 \\
\text { I IO } 9 \pm 3 \cdot 7\end{array}$ \\
\hline Mean weight & $\begin{array}{l}\text { p } \\
0\end{array}$ & $\begin{array}{l}\mathrm{I} \cdot 22 \pm 0 \cdot 06 \\
0.89 \pm 0 \cdot 04\end{array}$ & $\begin{array}{l}\mathrm{I} \cdot 24 \pm 0.04 \\
0.87 \pm 0.05\end{array}$ & $\begin{array}{l}\mathrm{I} \cdot \mathrm{I} 4 \pm 0 \cdot 05 \\
0.84 \pm 0 \cdot 04\end{array}$ \\
\hline Born per $3 \frac{1}{2}$ days & $\begin{array}{l}\text { 우 } \\
\text { ơ }\end{array}$ & $\begin{array}{l}69 \cdot 9 \pm 2 \cdot 4 \\
45 \cdot 8 \pm \mathrm{I} \cdot 7\end{array}$ & $\begin{array}{l}5 \mathrm{I} \cdot 6 \pm \mathrm{I} \cdot 8 \\
36 \cdot 6 \pm \mathrm{r} \cdot 3\end{array}$ & $\begin{array}{l}66 \cdot 9 \pm \mathrm{I} \cdot 7 \\
42 \cdot 4 \pm \mathrm{r} \cdot 3\end{array}$ \\
\hline Weight per $3 \frac{1}{2}$ days & $\begin{array}{l}\text { 웅 } \\
\text { ot }\end{array}$ & $\begin{array}{l}80 \cdot 8 \pm 2 \cdot 9 \\
39 \cdot 1 \pm \mathrm{I} \cdot 6\end{array}$ & $\begin{array}{l}59^{\circ} 0 \pm 2 \cdot 2 \\
29^{\circ} 8 \pm 1 \cdot 2\end{array}$ & $\begin{array}{l}72 \cdot 0 \pm 2 \cdot 0 \\
33 \cdot 7 \pm 1 \cdot 2\end{array}$ \\
\hline Mean weight, newborn & $\begin{array}{l}\text { o } \\
\text { a }\end{array}$ & $\begin{array}{l}I \cdot I 6 \pm 0 \cdot 06 \\
0 \cdot 85 \pm 0 \cdot 05\end{array}$ & $\begin{array}{l}\mathrm{I} \cdot \mathrm{I} 4 \pm 0.05 \\
0.81 \pm 0.04\end{array}$ & $\begin{array}{l}\mathrm{I} \cdot 08 \pm 0 \cdot 04 \\
0.79 \pm 0.04\end{array}$ \\
\hline
\end{tabular}

monomorphic $\mathrm{CH}$ populations mostly fall short of statistical significance, while those between the monomorphic $\mathrm{CH}$ and $\mathrm{AR}$ populations are quite significant, and so are the differences between the polymorphic and the monomorphic AR populations.

Table I shows also the mean weights of the newly hatched females and males, and of the females and males in the adult ovipositing populations. These data are suggestive in several respects. A newlyhatched female is found to weigh about I. I mg., and a newly-hatched male about $0.8 \mathrm{mg}$. In the experiments of Beardmore, Dobzhansky and Pavlovsky (1960, tables 3, 4 and 5), females weighed o.8-0.9 mg., and males $0 \cdot 7-0 \cdot 8 \mathrm{mg}$. These figures are not strictly comparable, since in the experiments of Beardmore $e t$ al., the flies were weighed at an average age of less than one day, and in the present experiments they were weighed at an average age of about $\mathrm{I} \cdot 5$ days. The figures, nevertheless, suggest that in the present experiments the flies were larger, and this is in accord with our visual impression. This is as it should be, since the larvæ in the bottle populations are much less crowded and have more abundant food than they do in the cage populations. On the other hand, the flies in the adult ovipositing 
populations were only slightly heavier than were the freshly hatched flies (about I.2 mg. instead of I.I mg. per female, less than $0.9 \mathrm{mg}$. instead of $0.8 \mathrm{mg}$. per male, see table $\mathrm{I}$ ). The crowding of the adults in a single bottle evidently prevented them from securing enough food and from gaining much weight.

\section{THE SECOND EXPERIMENT}

The polymorphic population No. 181, and the monomorphic AR (No. 180), and $\mathrm{CH}$ (No. 182) populations, were established originally from the same source as Nos. 173,175 and 177 . However, the " $180-$ series" spent some months at a lower temperature ( $16^{\circ} \mathrm{C}$.), and were

TABLE 2

Number and weight (in mg.) of the fies in the populations. Second experiment

\begin{tabular}{|c|c|c|c|c|}
\hline & & $\begin{array}{l}\text { Polymorphic } \\
\mathrm{AR} / \mathrm{CH}(\mathrm{I} 8 \mathrm{I})\end{array}$ & $\begin{array}{l}\text { Monomorphic } \\
\operatorname{AR}(180)\end{array}$ & $\begin{array}{l}\text { Monomorphic } \\
\mathrm{CH}(182)\end{array}$ \\
\hline Total population & $\begin{array}{l}90 \\
00 \\
00\end{array}$ & $\begin{array}{l}184.3 \pm 5.6 \\
115.5 \pm 5.5\end{array}$ & $\begin{array}{r}139 \cdot 1 \pm 6 \cdot 1 \\
74 \cdot 3 \pm 4 \cdot 5\end{array}$ & $\begin{array}{l}169.2 \pm 7.5 \\
101 \cdot 8 \pm 5.9\end{array}$ \\
\hline Total weight & $\begin{array}{l}\text { of } \\
\text { co }\end{array}$ & $\begin{array}{l}221 \cdot 9 \pm 6 \cdot 1 \\
103 \cdot 4 \pm 5 \cdot 2\end{array}$ & $\begin{array}{r}168 \cdot 3 \pm 6 \cdot 9 \\
62 \cdot 8 \pm 3 \cdot 9\end{array}$ & $\begin{array}{r}204 \cdot 1 \pm 9 \cdot 3 \\
89.3 \pm 5.8\end{array}$ \\
\hline Mean weight & $\begin{array}{l}q \\
0 \\
0\end{array}$ & $\begin{array}{l}1 \cdot 20 \pm 0.05 \\
0.90 \pm 0.05\end{array}$ & $\begin{array}{l}1 \cdot 21 \pm 0.06 \\
0.85 \pm 0.09\end{array}$ & $\begin{array}{l}\mathrm{I} \cdot 2 \mathrm{I} \pm 0.06 \\
0.88 \pm 0.07\end{array}$ \\
\hline Born per $3 \frac{1}{2}$ days & $\begin{array}{l}q 9 \\
\text { की } \\
\text { ôt }\end{array}$ & $\begin{array}{l}59 \cdot 3 \pm 2 \cdot 0 \\
38 \cdot 2 \pm 1 \cdot 6\end{array}$ & $\begin{array}{l}46 \cdot 1 \pm 2 \cdot 0 \\
26 \cdot 2 \pm 1 \cdot 4\end{array}$ & $\begin{array}{l}52 \cdot 0 \pm 2 \cdot 0 \\
32 \cdot 2 \pm 1 \cdot 7\end{array}$ \\
\hline Weight per $3 \frac{1}{2}$ days & $\begin{array}{l}99 \\
090 \\
00\end{array}$ & $\begin{array}{l}66 \cdot 4 \pm 2 \cdot 2 \\
32 \cdot 9 \pm 1 \cdot 4\end{array}$ & $\begin{array}{l}48 \cdot 7 \pm 2 \cdot 2 \\
20 \cdot 9 \pm 1 \cdot 1\end{array}$ & $\begin{array}{l}59 \cdot 6 \pm 2 \cdot 4 \\
28 \cdot 1 \pm 1 \cdot 6\end{array}$ \\
\hline Mean weight, newborn & $\frac{q}{0}$ & $\begin{array}{l}1 \cdot 12 \pm 0.05 \\
0.86 \pm 0.05\end{array}$ & $\begin{array}{l}\text { I.06 } \pm 0.06 \\
0.80 \pm 0.06\end{array}$ & $\begin{array}{l}1.15 \pm 0.06 \\
0.87 \pm 0.07\end{array}$ \\
\hline
\end{tabular}

then returned to $25^{\circ} \mathrm{C}$. The two "series" of populations behaved somewhat differently ( $c f$. Beardmore, Dobzhansky and Pavlovsky, 1960). As shown in table 2, the " 180 -series" contained and produced consistently somewhat fewer flies than the "I 70 -series" (table I). However, the three populations of each series are quite comparable.

Table 2 shows that the polymorphic population (No. 18I) contained more flies of both sexes, and produced more flies per unit time, than the monomorphic $\mathrm{CH}$ (No. 182), and this latter contained and produced more flies than the monomorphic AR (No. I80). The differences between Nos. 181 and 182 are quite consistent, although some of them do not reach the conventional level of statistical significance. The differences between Nos. 182 and 180 , and a fortiori between Nos. 181 and 182 , are significant. On the other hand, the mean weights of a fly are about the same in all populations.

The results of the first and the second experiments (the two "series" of the populations) are mutually consistent. 


\section{LONGEVITY}

In a population at equilibrium, the mean numbers of births and of deaths per unit time are equal. The mean numbers of the flies in the populations, and the mean numbers of the flies born per unit time being known, the mean longevity of the flies in the experimental populations can be calculated. The calculation raises some statistical problems, which Professor Howard Levene has kindly consented to discuss in the Appendix to the present paper. The estimates are reported in table 3 .

The longevity of the females is slightly but consistently greater than that of the males. The longevity of either sex is greatest in the monomorphic $\mathrm{CH}$ populations, intermediate in the polymorphic, and lowest

TABLE 3

Estimated mean longevity, in days, of the adult fies in the population

\begin{tabular}{|c|c|c|c|}
\hline Population & & Females & Males \\
\hline $\begin{array}{l}\text { No. I73, Polymorphic } \\
\text { No. I75, Monomorphic AR } \\
\text { No. I77, Monomorphic CH } \\
\text { No. I81, Polymorphic } \\
\text { No. I80, Monomorphic AR } \\
\text { No. I82, Monomorphic CH }\end{array}$ & $\dot{\dot{v}} \dot{ } \dot{ }$ & $\begin{array}{l}\text { I } 2 \cdot 05 \\
\text { II } \cdot 70 \\
\text { I } 2 \cdot 50 \\
\text { I } 2 \cdot 04 \\
\text { II } \cdot 72 \\
\text { I } 2 \cdot 55\end{array}$ & $\begin{array}{l}\text { II } \cdot 85 \\
11 \cdot 30 \\
12 \cdot 06 \\
\text { II } \cdot 74 \\
11 \cdot 09 \\
12 \cdot 22\end{array}$ \\
\hline
\end{tabular}

in the monomorphic AR populations. All the longevities in our experimental populations are much lower than in flies of the same species and at the same temperature but under near-optimal conditions (cf. Vetukhiv, I957).

\section{DISCUSSION}

In the present experiments, like in those of Beardmore, Dobzhansky and Pavlovsky (ig6o), chromosomally polymorphic populations evince a higher fitness than do the chromosomally monomorphic ones. The polymorphic populations contain more individuals, and a greater biomass, than the monomorphics. The polymorphic populations utilise their environments more efficiently. The mean size and the mean longevity of an individual are, however, not very different in the polymorphic and monomorphic populations.

As pointed out in the Introduction, the environments which the populations were called upon to master were different in the experiments of Beardmore, Dobzhansky and Pavlovsky and in the present experiments. In the former, the larvæ were exposed to extreme crowding, while the adults were relatively uncrowded, while in the present ones the conditions are reversed. This environmental difference is reflected in the results. While in the former experiments the monomorphic $\mathrm{CH}$ populations were inferior to the monomorphic $\mathrm{AR}$, in 
the present ones $\mathrm{CH}$ is clearly superior to $\mathrm{AR}$, and, in point of fact, not much below the polymorphic populations.

The reversal of the relative adaptive values of the monomorphic $\mathrm{CH}$ and $\mathrm{AR}$ populations is, we believe, quite significant ecologically. In the populations of the localities in California from which the wild progenitors of our experimental flies came, the relative frequencies of chromosomes with the $\mathrm{CH}$ gene arrangement increase during the spring but decrease during the summer (Dobzhansky, 1947). Another class of chromosomes, ST, wane during the spring and wax during the summer. The AR chromosomes are relatively stable in frequency. Now, in the experimental populations kept in population cages the homozygous ST/ST class is more fit than AR/AR, and the latter is fitter than $\mathrm{CH} / \mathrm{CH}$ (at $25^{\circ} \mathrm{C}$.), whereas the fitnesses of all of them are approximately equal at $16^{\circ} \mathrm{C}$. (Dobzhansky, 1948). Yet under natural conditions in spring, $\mathrm{CH} / \mathrm{CH}$ must be more fit than $\mathrm{AR} / \mathrm{AR}$ and ST/ST, since the frequency of the $\mathrm{CH}$ class is on the increase. The experiments of Birch (1955) have been the first to shed needed light on this situation. Birch showed that when the crowding of the larvæ is eliminated, the $\mathrm{CH} / \mathrm{CH}$ karyotype is superior in fitness to $\mathrm{ST} / \mathrm{ST}$. Our results may, then, be regarded as a confirmation and extension of those of Birch. In the population cages the competition among larvæ for food is severe, while in our "bottle populations" the competition is transferred to the adult stage. The inversion of the fitness order from $\mathrm{AR} / \mathrm{AR}>\mathrm{CH} / \mathrm{CH}$ in the experiments of Beardmore, Dobzhansky and Pavlovsky ( $\mathrm{I}$ 960) to $\mathrm{CH} / \mathrm{CH}>\mathrm{AR} / \mathrm{AR}$ in the present experiments is thus explained.

\section{SUMMARY}

Experimental populations of Drosophila pseudoobscura were made polymorphic and monomorphic for the $\mathrm{AR}$ and $\mathrm{CH}$ gene arrangements in their third chromosomes. In contrast to the previous experiments of Beardmore, Dobzhansky and Pavlovsky (1960), in which the larvæ were crowded and the adult flies relatively uncrowded, in the present experiments the adults were crowded and the larvæ relatively uncrowded. The chromosomally polymorphic populations proved to be superior to the chromosomally monomorphic ones; the former produced more flies and a greater biomass, although the average weights of the individual flies were about alike. In the experiments of Beardmore, Dobzhansky and Pavlovsky (loc. cit.) the monomorphic AR/AR were superior to the monomorphic $\mathrm{CH} / \mathrm{CH}$ populations. In the present experiments this order is reversed. The bearing of this reversal on the seasonal changes in the genetic constitution which the populations undergo in their natural habitats is pointed out.

Acknowledgments. - We are obligated to Professor H. L. Carson, of the Washington University, St Louis, for advice concerning the experimental technique, to Professors Howard Levene of Columbia University and L. G. Birch of the University of Sydney for useful discussions, and to Mrs. Angela Drescher for help with the calculations. 


\section{REFERENCES}

BeARDMORE, J. A., DOBZHANSKY, TH., AND PAVlovsky, o. A. 196o. An attempt to compare the fitness of polymorphic and monomorphic experimental populations of Drosophila pseudoobscura. Heredity, 14, 19-33.

BIRCH, L. C. 1955. Selection in Drosophila pseudoobscura in relation to crowding. Evolution, 9, 389-399.

BUzZATI-TRAVERSO, A. A. 1955. Evolutionary changes in components of fitness and other polygenic traits in Drosophila melanogaster populations. Heredity, 9, 153* 186.

CARSON, H. L. 1958. Increase in fitness in experimental populations resulting from heterosis. Proc. Nat. Acad. Sci., 44, 11 36-1 141 .

DOBZHANSKY, TH. 1947. A directional change in the genetic constitution of a natural population of Drosophila pseudoobscura. Heredity, $1,53^{-6} 6$.

DOBZHANSKY, тн. 1948. Genetics of natural populations. XVIII. Genetics, $33,588-602$.

VETUKHIV, M. A. 1957. Longevity of hybrids between geographic populations of Drosophila pseudoobscura. Evolution, II, 348-36o.

\section{APPENDIX \\ HOWARD LEVENE \\ Departments of Mathematical Stat/stics and Zoology, Columbia University}

The estimation of longevity. If the birth process and death process are both continuous stationary stochastic processes of an arbitrary kind, the mean longevity is equal to the mean number of living individuals, $\mathcal{N}$, divided by the mean number born per unit interval of time, $B$. In the present case the death process is approximately continuous : that is individuals die one by one at random times. However, the birth process is essentially discrete. For the present purpose " birth" is not the time of biological birth, but the time at which an individual enters the population. Individuals enter the population in batches, alternately all flies born and surviving in a 3-day period and all flies born and surviving in a 4 -day period. Since "births" are only counted on addition of flies, for mathematical purposes flies are born when they are added, and deaths only begin at that time. If mean longevity were long, compared with the interval between births, this would matter little, but in the present experiment the mean longevity is only about three times the mean interval between births. Accordingly a correction factor must be introduced.

The correction factor will depend on the distribution of time of death. We will use the simplest such distribution, the exponential, where the probability an individual born at time zero dies by time $t$ is $\mathrm{I}-e^{-t / m}$, where $m$ is the mean longevity expressed in the same units as $t$. This distribution arises if the probability a fly alive at time $t$ dies between $t$ and $t+\Delta t$ is $\Delta t / m$ regardless of the age of the fly. Since in the present experiment most flies die well before old age as a result of overcrowding, in large part from purely accidental causes, this model may not be too far in error.

If flies had been added at uniform time intervals $c$, the expected number of flies present at the beginning of the interval that die during it is $(\mathcal{N}+B)$ $\left(\mathrm{I}-e^{-c / m}\right)$, and the proportion remaining alive would be $\mathcal{N}=(\mathcal{N}+B) e^{-c / m}$, 
where $(\mathcal{N}+B)$ is the number alive at the beginning of the period. When a stable population size is reached, the number of individuals "born" at the beginning of each period must be $B=(\mathcal{N}+B)\left(1-e^{-c / m}\right)$, giving

$$
(\mathcal{N}+B) e^{-c / m}+(\mathcal{N}+B)\left(1-e^{-c / m}\right)=(\mathcal{N}+B)
$$

at the start of the next period.

We then have the crude measure of mean longevity in terms of the time interval $c$ as our unit,

$$
\frac{a}{c}=\frac{\mathcal{N}}{B}=\frac{\mathcal{N}_{e^{-c / m}}}{\mathcal{N}\left(\mathrm{I}-e^{-c / m}\right)}=\frac{e^{-c / m}}{\mathrm{I}-e^{-c / m}} \neq \frac{m}{c},
$$

where $m$ is the true mean longevity and $a$ the crude measure, both in the original units of time. The closeness of $a$ to $m$ depends on the ratio $r=m / c$, being closer the larger the mean longevity is relative to the intervals $c$. This can be seen by evaluating the expression (I) numerically; however, by expanding the exponentials in ( $\mathrm{I}$ ) in power series, simplifying, and dividing algebraically, it can be shown that

$$
r=\frac{m}{c}=\frac{a}{c}+\frac{\mathrm{I}}{2}-\frac{\mathrm{I}}{\mathrm{I} 2 r}+\frac{\mathrm{I}}{24 r^{2}}-\ldots .
$$

Furthermore the error committed by stopping with any number of terms on the right side of this expression is less than the first term omitted.

In the present situation we have noted that $r$ is approximately 3 , and we have

$$
\frac{m}{c}-\frac{a}{c}=\frac{1}{2}-\frac{1}{(12)(3)}+\frac{1}{(24)(3)^{2}}=0.5-0.02778+0.00463,
$$

so that the first correction term, $\mathbf{0 . 5}$, is important, but the others are not.

The actual situation in the present experiments is more complicated, since two different time intervals, $c=3$ days and $d=4$ days are involved in alternation. Counting of survivors was always done before addition of " new-born" flies after the shorter period (e.g. if flies were added on Monday and Thursday, counting was done on Thursday before the addition of new flies). Now we must let $b=$ the mean number of flies born per day, so that the number born in a period of $c$ days is $c b$ and the number born in a period of $d$ days is $d b$. Then at equilibrium we must have the relationship

$$
\mathcal{N}=\left[(\mathcal{N}+c b) e^{-d / m}+d b\right] e^{-c / m} .
$$

Since the crude measure of longevity is $a=\mathcal{N} / b$ in days, we have $\mathcal{N}=a b$, and substituting in (3) we have

$$
a b=\left[(a+c) b e^{-d / m}+d b\right] e^{-c / m} .
$$

Dividing both sides by $b, b$ no longer appears, and solving for $a$ gives

$$
a=\frac{c e^{-\frac{c+d}{m}}+d e^{-\frac{e}{m}}}{1-e^{-\frac{c+d}{m}}}=\frac{3 e^{-\eta / m}+4 e^{-3 / m}}{\mathrm{r}-e^{-7 / m}}
$$

for our special case. Setting $c=d$, and $e^{-2 c / m}=\left(e^{-c / m}\right)^{2}$ it can be shown that the first expression in (5) reduces to $c$ times the expression (I) as it 
should. It is easily shown algebraically or numerically that for this case also $(m-a)$ is nearly constant for small variations in $m$. Thus for $m=\mathbf{I}$, $m-a=\mathrm{I} \cdot 159 \mathrm{I}$, while for $m=\mathrm{I} 2 \cdot 6, m-a=\mathrm{I} \cdot \mathrm{I} 656$.

In the present study, the crude longevity is obtained by dividing the mean number of flies present by the mean number born per 3.5 days and multiplying by 3.5 in tables $\mathrm{I}$ and 2 , giving crude $a$ 's. For the range of $a$ values found, this can be corrected to estimate $m$ with two decimal accuracy, by simply adding $\mathrm{I} \cdot \mathrm{I}$, and this has been done in table 3 .

It should be noted that the corrections are based on a death rate independent of age. If the death rate increases with age the correction required will be smaller. If the death rate is high at first, then low, and finally increases, the correction will be closer to that for constant rate. Since it is reasonable to assume a fairly constant death rate in this experiment, the corresponding correction has been used.

It may also be noted that these longevities are measured from the time the flies are placed in the crowded cultures. On the average, flies are about $1 \cdot 75$ days old when added. There is also some early unrecorded mortality in the bottles where the flies are born. 